\title{
The School Environment is a Mixed blessing for Seventh-Graders with Autism Spectrum Disorder in Taiwan: A Cohort Study
}

Hsin-Hui Lu ( $\sim$ hsinhuilupsy@gmail.com )

Chung Shan Medical University https://orcid.org/0000-0001-8583-591X

\section{Duan-Rung Chen}

National Taiwan University

An-Kuo Chou

National Taiwan University Hospital

\section{Research Article}

Keywords: bullying, autism spectrum disorder, school environment, adolescents.

Posted Date: December 1st, 2021

DOI: https://doi.org/10.21203/rs.3.rs-1115475/v1

License: (1) (i) This work is licensed under a Creative Commons Attribution 4.0 International License.

Read Full License 


\section{Abstract}

Background : There is strong evidence to support the association between bullying and the onset of mental health conditions in students with ASD. In Taiwan, seventh grade marks the first year in middle school after elementary school. It is also a period when peers tend to affiliate with one another to perform bullying behaviors to establish status among the peer group. Therefore, it is considered one of the most challenging times for students with ASD due to several adjustments within the school environment and the developmental changes that arise at this age.. To assess the association between school environment and bullying victimization among students with autism spectrum disorder (ASD) studying in regular classes in the first year of middle school.

Methods: Data were obtained from the Special Needs Education Longitudinal Study database located in the Survey Research Data Archive of Academia Sinica. One hundred and eighty-four seventh-graders with ASD in regular classes across Taiwan were included in the analysis. The primary variables under study were whether they had experienced social exclusion, insults or teasing, extortion, or sexual harassment over the past semester.

Results: Participants with a higher positive friendship quality $(P=0.027)$ and who had received more peer support upon encountering difficulties in school $(P=0.041)$ were less likely to experience social exclusion. Participants with higher positive friendship quality $(P=0.001)$ and a more positive learning environment in the classroom $(P=0.031)$ were less likely to have experienced insults or teasing. However, participants with more friends were more likely to be extorted $(P=0.015)$ and sexually harassed $(P=$ $0.001)$ than those with fewer friends. Furthermore, participants in regular classes on a part-time basis were 2.59 times more likely to report sexual harassment than those in regular classes on a full-time basis $(P=0.021)$.

Conclusions : This study suggests that a supportive school environment reduces the likelihood that seventh-graders with ASD are bullied. Clinicians should consider the association between the school environment and bullying victimization among adolescents with ASD in regular classes during their first year of middle school.

\section{Introduction}

Adolescents with special educational needs are more likely to be bullying victims than their classmates without such disabilities [1]. Individual with ASD has a considerably greater risk of being victimized than their peers without, a trend that applies from childhood to adulthood [2]. Studies have suggested that a combination of individual vulnerabilities in students with ASD, such as communication problems, stereotypical behaviors and interests, tendencies toward psychological distress, and aggressive behaviors, may lead to bullying victimization [3-8]. During adolescence, bullying victimization by schoolmates can result in multiple health problems, especially for individuals with autism spectrum disorder (ASD) $[9,10]$. There is strong evidence to support the association between bullying and the onset 
of mental health conditions such as panic disorder, major depression, loneliness, and social anxiety in students with ASD $[5,11,12]$.

The social-ecological diathesis-stress model conceptualizes bullying as an interaction between the individual vulnerabilities (e.g., less social competence or fewer friends) of the victim and their environment $[13,14]$. The association between bullying victimization and the school environment among typically developing children and adolescents comprises multiple factors, including parental engagement in school affairs, positive interpersonal interactions, peer social support, and the quality of friendships $[15,16]$. The school environment has been associated with increased exposure to bullying among students with ASD $[9,17,18]$. However, whether protective measures against bullying in the school environment would be effective for Taiwanese students with ASD arranged in regular classes during the first year of middle school has yet to be determined.

In Taiwan, seventh grade marks the first year in middle school after elementary school. It is considered one of the most challenging times for students with ASD due to several adjustments within the school environment and the developmental changes that arise at this age. It is also a period when peers tend to affiliate with one another to perform bullying behaviors to establish status among the peer group [19]. Students with ASD have more significant social interactions and communication difficulties. Their maladaptive functioning exacerbates these difficulties when entering new social groups, particularly during the first year of the elementary-to-middle-school transition period [20]. Furthermore, the influence of environmental factors in schools on bullying victimization for seventh-graders with ASD has yet to be well examined $[9,17,18,21]$. School administrations need to implement adequate measures to protect adolescents with ASD against bullying in their first year of middle school and reduce their risk of developing future mental health problems.

The present study investigates how the school environment is associated with bullying victimization among seventh-graders (aged 12-13 years) with ASD. Bullying victimization widely adopted in other studies $[22,23]$ was employed in this study. We examined four types of bullying victimization separately: social exclusion, insults or teasing, extortion, sexual harassment, and relationships with the school environment while controlling for individual variables. The following variables assessed the school environment: 1 ) the number of friends; 2) friendship quality; 3 ) classroom climate; 4) receiving assistance when difficulties occurred; 5) the teacher's attitude toward class integration; 6) parental engagement in children's learning, and 7) the amount of integration within regular classes. All analyses were controlled for the participants' sex, body mass index (BMI), learning capability, and levels of psychological distress.

\section{Methods}

\section{Participants}

Study sample. The study cohort sample was taken from the Special Needs Education Longitudinal Study (SNELS) database, which was released in 2011 from the Survey Research Data Archive of Academia 
Sinica (https://srda.sinica.edu.tw/index.php). The Institutional Review Board has approved the data application and analysis. In the SNELS, representative samples of students with ASD were randomly selected from a list of registrants. Specifically, they were identified from medical records or records held by the Special Education Needs Committees of local governments, as described in a previous study [24]. In the SNELS, data were obtained from questionnaires administered online, which both students and teachers filled in. The students completed their questionnaires independently, with the teachers providing aid if necessary. Fig. 1 displays the process used for participant selection. Of the 317 seventh-graders with ASD involved in the SNELS study in 2011, 223 studied in regular classes in general education schools. Thirty-nine seventh-graders with ASD were excluded due to a lack of data regarding the studied variables. Overall, 184 seventh-graders (167 boys) with ASD were enrolled in this study.

\section{Types of Victimization}

The students were asked whether they had experienced social exclusion, insults or teasing, extortion, or sexual harassment over the past semester. Social exclusion was assessed by asking the students, "Have you felt left out by your classmates at this school?" Being insulted or teased was measured by asking the students, "Have you felt insulted or teased by your classmates at this school?" Being extorted was assessed by asking the students, "Have you been extorted for money at this school?" Being sexually harassed was measured by asking the students, "Has anyone touched your body inappropriately and made you feel uncomfortable at this school?" Students recorded their responses using a four-point Likert scale $(1=$ never, $2=$ seldom, $3=$ occasionally, and $4=$ frequently $)$ to indicate the frequency of bullying victimization. Answers of "never" were coded as 0 , and all other responses were coded as 1.

\section{Student Characteristics}

Student characteristics comprised of the following variables: (a) sex, collected from teachers, with males and females coded 1 and 0 , respectively; (b) BMl, collected from teacher reports, was calculated as weight in kilograms divided by the square of their height in meters; (c) the general tendency of the students' learning capability in school was collected from teacher reports. The variable of students' learning capability in school was assessed using the following ten items: 1) paying attention in class, 2) complying with instructions, 3) sitting still, 4) participating in classroom discussions, 5) having the initiative to ask questions, 6) answering teachers' questions, 7) focusing on schoolwork, 8) having the motivation to learn, 9) finishing homework on time, and 10) collaborating with peers to complete tasks. These items were scored on a four-point Likert scale $(1=$ never, $2=$ seldom, $3=$ occasionally, and $4=$ frequently). Cronbach's a for the ten criteria was 0.86 . Psychological distress was self-reported using a six-item index adapted from the Symptom Checklist-90-Revised (SCL-6) instrument, originally developed to assess a broad range of psychological symptoms [25]. The criteria were extracted based on the most frequent symptoms experienced by students receiving special education services [26]. Each of the following six dimensions comprised one item of the SCL-6: depression (feeling downcast and lonely), obsessive compulsion (trouble concentrating), insomnia (restlessness or disturbed sleep), anxiety (feeling tense or uptight), psychoticism (never feeling close to another person), and anger/hostility (experiencing 
the urge to break or smash objects or beat, injure, or harm others). The frequency of each item was rated on the same four-point scale used to assess the frequency of victimization incidents. Cronbach's a for the SCL-6 was 0.88 .

\section{School Environment Characteristics}

Seven variables measured the characteristics of the school environment. First was the number of friends students had, which was assessed using responses to "How many classmates or friends do you usually hang out with?" on a scale of 1-5 (1: no friends, 2: one friend, 3: two or three friends, 4: four or five friends, and 5: six or more friends). The second, friendship quality, was measured by teachers' responses to the question, "Is the student able to get along well with other students in the class?" on a scale of 1-5 (1: no interaction at all, 2: poorly, 3: not very well, 4: acceptably well, and 5: very well). The third, classroom climate, was measured by teachers' responses to the following criteria: "The majority of the students proactively participate in inter-class competitions and activities," "The students have positive relationships with one another," "The students are helpful to and caring toward one another," and "The students collaborate (i.e., discuss their homework together)" using a scale of 1-4 (1: not at all true, 2: not very true, 3: somewhat true, and 4: very true). The fourth variable was whether students received assistance when difficulties occurred, which was measured by how students responded to the question, "Are you able to get help from anyone when encountering difficulties?" using a scale of 1-4 (1: almost no one, 2: very few people, 3: some people, and 4: many people). Variable five, the teacher's attitude toward class integration, was assessed by teachers' responses to the following phrases, "Schools should not exclude students with disabilities in student enrollment"; "Students with disabilities should be allowed to learn with their typically developing counterparts as much as possible"; "Regular class teachers should not neglect the needs of typically developing students in class because of the presence of students with disabilities"; "The placement of students with disabilities in the same class as that of typically developing students is beneficial for both types of students"; "The teacher's attitude is a key factor that affects the learning and adaptation of students with disabilities," and "Teaching students with disabilities is a responsibility shared by both special and regular class teachers" using a scale of 1-4 (1: strongly disagree, 2: somewhat disagree, 3: somewhat agree, and 4: strongly agree). The sixth variable, parental engagement in children's learning, was measured by teachers' responses to "How would you describe the involvement of this student's parents in their learning?" using a scale of 1-4 (1: nonexistent, 2: not very high, 3: moderately high, and 4: very high). The final variable, the amount of integration within regular classes, was measured by whether the students participate in classes full-time (coded as 0 ) or part-time (coded as 1). Those who were part-time in regular classes underwent special education sessions at other times.

\section{Data Analysis}

All analyses were performed using the IBM SPSS Statistics program for Windows, version 22 (IBM Corp., Armonk, NY, USA). First, participant demographics and differences in the school environment between the participants who had not experienced bullying were analyzed. Continuous variables were analyzed using independent sample t-tests, and categorical variables were compared using the chi-square test. Next, four 
separate hierarchical logistic regression analyses were conducted to examine the association between aspects in the school environment and the following types of bullying victimization: social exclusion, insults or teasing, extortion, and sexual harassment. Student characteristics were input into the models to assess their initial effects on bullying victimization. After adjusting for individual factors, the variables concerning aspects of the school environment were entered and analyzed.

\section{Results}

\section{Sample Characteristics}

Table 1 presents both the individual and school environmental aspects of the sample population. Among the 184 participants, $72.28 \%$ had experienced social exclusion, $70.11 \%$ had experienced insults or teasing, $6.52 \%$ had experienced extortion, and $28.26 \%$ had experienced sexual harassment. In contrast, only $14.13 \%$ had not experienced any bullying over the past semester. Overall, during the first year of middle school, approximately $85 \%$ had experienced at least one kind of bullying, and $66.85 \%$ had experienced at least two types. 
Table 1

Demographic Characteristics of the Study Sample $(N=184)$

\begin{tabular}{|c|c|c|c|c|}
\hline & $n$ & $\%$ & Mean & SD \\
\hline \multicolumn{5}{|l|}{ Types of bullying victimization } \\
\hline Social exclusion & 133 & 72.28 & & \\
\hline Insults or teasing & 129 & 70.11 & & \\
\hline Extortion & 12 & 6.52 & & \\
\hline Sexual harassment & 52 & 28.26 & & \\
\hline \multicolumn{5}{|c|}{ Number of types of bullying victimization experienced } \\
\hline Never & 26 & 14.13 & & \\
\hline One type & 35 & 19.02 & & \\
\hline Two types & 81 & 44.02 & & \\
\hline Three types & 39 & 21.20 & & \\
\hline Four types & 3 & 1.63 & & \\
\hline \multicolumn{5}{|l|}{ Individual characteristics } \\
\hline Sex: male & 167 & 90.76 & & \\
\hline Sex: female & 17 & 9.24 & & \\
\hline BMI & & & 21.64 & 4.27 \\
\hline Learning capability & & & 2.04 & 0.57 \\
\hline Psychological distress & & & 2.23 & 0.66 \\
\hline \multicolumn{5}{|l|}{ School environment characteristics } \\
\hline Number of friends & & & 2.69 & 1.30 \\
\hline Friendship quality & & & 3.66 & 0.87 \\
\hline Classroom climate & & & 2.40 & 0.45 \\
\hline Receiving assistance when difficulties occurred & & & 2.79 & 0.82 \\
\hline Teachers' integration-related attitudes & & & 2.40 & 0.55 \\
\hline Parental engagement & & & 3.62 & 0.61 \\
\hline Integration: full-time & 69 & 37.50 & & \\
\hline Integration: part-time & 115 & 62.50 & & \\
\hline
\end{tabular}




\section{Comparison of Those Who Had and Had Not Experienced Bullying Victimization}

As Table 2 indicates, participants who experienced social exclusion had greater psychological distress ( $t$ $(182)=3.90, P<0.001, d=0.64)$, fewer friends $(t(182)=-2.80, P=0.006, d=0.46)$, and lower positive friendship quality $(t(134.37)=-3.81, P<0.001, d=0.63)$ compared with those who did not. Moreover, their classroom environments were more negative $(t(182)=-2.63, P=0.009, d=0.43)$ and they received less assistance in school $(t(182)=-3.88, P<0.001, d=0.64)$. Participants who experienced insults or teasing reported greater psychological distress $(t(182)=3.34, P=0.001, d=0.54)$ and lower positive friendship quality $(t(160.53)=-4.24, P<0.001, d=0.68)$ than those who had not. Furthermore, their classroom environments were more negative $(t(182)=-3.49, P=0.001, d=0.56)$ and they received less assistance when difficulties arose in school $(t(182)=-2.47, P=0.014, d=0.40)$. Teachers' attitudes were generally supportive toward class integration $(t(182)=-2.55, P=0.011, d=0.41)$. Compared with participants who had not experienced extortion, those who had experienced it reported having more friends $(t(182)=2.01, P=0.046, d=0.60)$. The participants who had and had not experienced sexual harassment differed in terms of sex ratio $\left(\chi^{2}(1)=4.63, P=0.044, d=0.32\right)$. Notably, participants who had experienced sexual harassment reported greater psychological distress than those who had not $(t$ $(182)=-2.30, P=0.023, d=0.38)$. 
Table 2

Chi-Square and t-Test Results of Bullying Victimization by Individual and School Environmental Characteristics $(\mathrm{N}=184)$

Social exclusion

Experienced $^{\mathrm{a}} \quad$ None $^{\mathrm{a}} \quad p^{-}$

$(n=133)$

$(n=$

51)

Individual characteristics

Sex: male

BMI

Learning capability

Psychological distress

School environment

characteristics

Number of friends

Friendship quality

Class climate

Receiving assistance when

difficulties occurred

Teachers' integration-

related attitudes

Parental engagement

Integration: full-time

Table 2 continued

Extortion

Experienced $^{\mathrm{a}} \quad$ None $^{\mathrm{a}} \quad \begin{aligned} & p- \\ & \text { value }^{\mathrm{b}}\end{aligned}$

$123(92.48)$
$21.76(4.17)$
$2.01(0.57)$

$2.34(0.62)$ value $^{\text {b }}$

Experienced

$(n=129)$
None $^{\mathrm{a}} \quad p-$

value $^{b}$ $(n=$

$55)$

\section{Insults or teasing}

1.000

(86.27)

$.254 \quad 117(90.70)$

50

(90.91)

21.30
$(4.52)$

.505

$21.72(3.96)$

21.48

(4.93)

.730

2.11

(0.58)

$2.02(0.56)$

2.09

(0.60)

.449

$\begin{array}{llll}1.94 & <.001 & 2.33(0.64) & 1.99 \\ (0.66) & & & (0.64)\end{array}$

.001

.001 


\begin{tabular}{|c|c|c|c|c|c|c|}
\hline & \multicolumn{3}{|c|}{ Social exclusion } & \multicolumn{3}{|c|}{ Insults or teasing } \\
\hline \multicolumn{7}{|l|}{ Individual characteristics } \\
\hline Sex: male & $11(91.67)$ & $\begin{array}{l}156 \\
(90.70)\end{array}$ & 1.000 & $51(98.08)$ & $\begin{array}{l}116 \\
(87.88)\end{array}$ & .044 \\
\hline BMI & $21.73(4.92)$ & $\begin{array}{l}21.64 \\
(4.23)\end{array}$ & .946 & $22.05(3.89)$ & $\begin{array}{l}21.49 \\
(4.41)\end{array}$ & .425 \\
\hline Learning capability & $1.93(0.68)$ & $\begin{array}{l}2.05 \\
(0.56)\end{array}$ & .471 & $2.02(0.55)$ & $\begin{array}{l}2.05 \\
(0.58)\end{array}$ & .799 \\
\hline Psychological distress & $2.42(0.98)$ & $\begin{array}{l}2.22 \\
(0.63)\end{array}$ & .315 & $2.34(0.57)$ & $\begin{array}{l}2.19 \\
(0.69)\end{array}$ & .163 \\
\hline \multicolumn{7}{|l|}{$\begin{array}{l}\text { School environment } \\
\text { characteristics }\end{array}$} \\
\hline Number of friends & $3.42(1.62)$ & $\begin{array}{l}2.64 \\
(1.27)\end{array}$ & .046 & $3.04(1.47)$ & $\begin{array}{l}2.55 \\
(1.21)\end{array}$ & .023 \\
\hline Friendship quality & $4.00(0.60)$ & $\begin{array}{l}3.63 \\
(0.88)\end{array}$ & .069 & $3.58(0.89)$ & $\begin{array}{l}3.69 \\
(0.86)\end{array}$ & .429 \\
\hline Class climate & $2.52(0.51)$ & $\begin{array}{l}2.39 \\
(0.45)\end{array}$ & .321 & $2.40(0.47)$ & $\begin{array}{l}2.40 \\
(0.45)\end{array}$ & .945 \\
\hline $\begin{array}{l}\text { Receiving assistance when } \\
\text { difficulties occurred }\end{array}$ & $3.00(0.85)$ & $\begin{array}{l}2.78 \\
(0.82)\end{array}$ & .367 & $2.79(0.85)$ & $\begin{array}{l}2.80 \\
(0.81)\end{array}$ & .958 \\
\hline $\begin{array}{l}\text { Teachers' integration- } \\
\text { related attitudes }\end{array}$ & $2.50(0.52)$ & $\begin{array}{l}2.39 \\
(0.55)\end{array}$ & .497 & $2.35(0.62)$ & $\begin{array}{l}2.41 \\
(0.52)\end{array}$ & .503 \\
\hline Parental engagement & $3.58(0.52)$ & $\begin{array}{l}3.62 \\
(0.61)\end{array}$ & .831 & $3.58(0.72)$ & $\begin{array}{l}3.64 \\
(0.56)\end{array}$ & .551 \\
\hline Integration: full time & $3(25.00)$ & $\begin{array}{l}66 \\
(38.37)\end{array}$ & .539 & $14(26.92)$ & $\begin{array}{l}55 \\
(41.67)\end{array}$ & .090 \\
\hline
\end{tabular}

\section{The School Environment Characteristics of Bullying Victimization}

Table 3 presents the determinants of experiencing social exclusion, insults or teasing, extortion, and sexual harassment over the past semester (Models 1-4). 
Table 3

Final Hierarchical Logistic Regression of Bullying Victimization ( $N=184$ )

\begin{tabular}{|c|c|c|c|c|c|c|c|c|}
\hline \multirow{2}{*}{$\begin{array}{l}\text { AORs [95\%Cl] } \\
\text { Individual characteristics }\end{array}$} & \multicolumn{2}{|c|}{$\begin{array}{l}\text { Social } \\
\text { exclusion }\end{array}$} & \multicolumn{2}{|c|}{$\begin{array}{l}\text { Insults or } \\
\text { teasing }\end{array}$} & \multicolumn{2}{|c|}{ Extortion } & \multicolumn{2}{|c|}{$\begin{array}{l}\text { Sexual } \\
\text { harassment }\end{array}$} \\
\hline & & & & & & & & \\
\hline Sex: male Ref $=$ female & 1.47 & $\begin{array}{l}{[0.44,} \\
4.90]\end{array}$ & 0.67 & $\begin{array}{l}{[0.19,} \\
2.44]\end{array}$ & 1.02 & $\begin{array}{l}{[0.11} \\
9.40]\end{array}$ & $8.44^{\star}$ & $\begin{array}{l}{[1.02,} \\
69.91]\end{array}$ \\
\hline BMI & 1.05 & $\begin{array}{l}{[0.96,} \\
1.15]\end{array}$ & 1.01 & $\begin{array}{l}{[0.93,} \\
1.11]\end{array}$ & 0.99 & $\begin{array}{l}{[0.84,} \\
1.16]\end{array}$ & 1.02 & $\begin{array}{l}{[0.94} \\
1.11]\end{array}$ \\
\hline Learning capability & 1.32 & $\begin{array}{l}{[0.62} \\
2.81]\end{array}$ & 1.54 & $\begin{array}{l}{[0.73} \\
3.26]\end{array}$ & 0.57 & $\begin{array}{l}{[0.17} \\
1.95]\end{array}$ & 1.15 & $\begin{array}{l}{[0.57} \\
2.29]\end{array}$ \\
\hline Psychological distress & $2.66^{\star \star}$ & $\begin{array}{l}{[1.37} \\
5.17]\end{array}$ & $2.59 \star \star$ & $\begin{array}{l}{[1.35,} \\
4.95]\end{array}$ & 2.24 & $\begin{array}{l}{[0.81} \\
6.15]\end{array}$ & 1.72 & $\begin{array}{l}{[0.98,} \\
3.04]\end{array}$ \\
\hline \multicolumn{9}{|c|}{ School environment characteristics } \\
\hline Number of friends & 0.83 & $\begin{array}{l}{[0.61,} \\
1.14]\end{array}$ & 1.06 & $\begin{array}{l}{[0.78} \\
1.44]\end{array}$ & $1.95^{\star}$ & $\begin{array}{l}{[1.14} \\
3.35]\end{array}$ & $1.66^{\star \star}$ & $\begin{array}{l}{[1.22,} \\
2.25]\end{array}$ \\
\hline Friendship quality & $0.55^{\star}$ & $\begin{array}{l}{[0.32,} \\
0.93]\end{array}$ & $0.40^{\star \star}$ & $\begin{array}{l}{[0.24,} \\
0.70]\end{array}$ & 1.55 & $\begin{array}{l}{[0.56,} \\
4.27]\end{array}$ & 0.73 & $\begin{array}{l}{[0.46,} \\
1.14]\end{array}$ \\
\hline Class climate & 0.52 & $\begin{array}{l}{[0.22,} \\
1.24]\end{array}$ & $0.39 *$ & $\begin{array}{l}{[0.17} \\
0.92]\end{array}$ & 2.58 & $\begin{array}{l}{[0.52,} \\
12.65]\end{array}$ & 1.46 & $\begin{array}{l}{[0.65} \\
3.30]\end{array}$ \\
\hline $\begin{array}{l}\text { Receiving assistance } \\
\text { when difficulties occurred }\end{array}$ & $0.57 *$ & $\begin{array}{l}{[0.33} \\
0.98]\end{array}$ & 0.87 & $\begin{array}{l}{[0.52,} \\
1.44]\end{array}$ & 1.09 & $\begin{array}{l}{[0.47} \\
2.53]\end{array}$ & 0.90 & $\begin{array}{l}{[0.56} \\
1.44]\end{array}$ \\
\hline $\begin{array}{l}\text { Teachers' integration- } \\
\text { related attitudes }\end{array}$ & 1.07 & $\begin{array}{l}{[0.53} \\
2.17]\end{array}$ & 0.69 & $\begin{array}{l}{[0.34,} \\
1.41]\end{array}$ & 1.46 & $\begin{array}{l}{[0.40,} \\
5.32]\end{array}$ & 1.03 & $\begin{array}{l}{[0.52,} \\
2.03]\end{array}$ \\
\hline Parental engagement & 0.81 & $\begin{array}{l}{[0.41} \\
1.59]\end{array}$ & 0.84 & $\begin{array}{l}{[0.43} \\
1.63]\end{array}$ & 0.78 & $\begin{array}{l}{[0.28,} \\
2.18]\end{array}$ & 0.92 & $\begin{array}{l}{[0.52} \\
1.64]\end{array}$ \\
\hline $\begin{array}{l}\text { Integration: part time Ref = } \\
\text { full time }\end{array}$ & 1.25 & $\begin{array}{l}{[0.55} \\
2.84]\end{array}$ & 1.71 & $\begin{array}{l}{[0.77} \\
3.83]\end{array}$ & 1.95 & $\begin{array}{l}{[0.40} \\
9.52]\end{array}$ & $2.59 *$ & $\begin{array}{l}{[1.16,} \\
5.80]\end{array}$ \\
\hline-2 Log likelihood & \multicolumn{2}{|l|}{177.63} & \multicolumn{2}{|l|}{182.76} & \multicolumn{2}{|l|}{87.33} & \multicolumn{2}{|c|}{194.95} \\
\hline Omnibus tests & \multicolumn{2}{|c|}{$\begin{array}{l}\chi^{2}(7)=23.00, P \\
=.002\end{array}$} & \multicolumn{2}{|c|}{$\begin{array}{l}\chi^{2}(7)=30.16, P \\
<.001\end{array}$} & \multicolumn{2}{|c|}{$\begin{array}{l}\chi_{(7)}^{2}=1.39, P= \\
.846\end{array}$} & \multicolumn{2}{|c|}{$\begin{array}{l}\chi^{2}(7)=16.15, P \\
=.024\end{array}$} \\
\hline
\end{tabular}

\section{Social Exclusion}

Participants who had higher positive friendship quality (adjusted odds ratio $[A O R]=0.55,95 \%$ confidence interval [CI]: $0.32-0.93, P=0.027)$ or had received more assistance when encountering difficulties in school (AOR $=0.57,95 \% \mathrm{Cl}: 0.33-0.98, P=0.041)$ were less likely to experience social exclusion. 
Additionally, participants who reported having greater psychological distress experienced more social exclusion than those who did not $(\mathrm{AOR}=2.66,95 \% \mathrm{Cl}: 1.37-5.17, P=0.004)$.

\section{Insults or teasing}

Participants who had higher positive friendship quality (AOR $=0.40,95 \% \mathrm{Cl}: 0.23-0.70, P=0.001)$ or were in more positive learning environments in the classroom ( $\mathrm{AOR}=0.39,95 \% \mathrm{Cl}: 0.17-0.92, P=0.031$ ) were less likely to experience insults or teasing. Furthermore, participants who reported greater psychological distress experienced insults or teasing more often than those who had less or no distress (AOR $=2.59,95 \% \mathrm{Cl}: 1.35-4.95, P=0.004)$.

\section{Extortion}

Participants who reported having more friends $(A O R=1.95,95 \% \mathrm{Cl}: 1.14-3.35, P=0.015)$ were more likely to have been extorted than those with fewer friends.

\section{Sexual Harassment}

Participants who reported having more friends $(\mathrm{AOR}=1.66,95 \% \mathrm{Cl}: 1.22-2.25, P=0.001)$ were more likely to have been sexually harassed than those with fewer friends. Furthermore, students in regular classes on a part-time basis were 2.59 times more likely to report sexual harassment than those in regular classes on a full-time basis $(\mathrm{AOR}=2.59,95 \% \mathrm{Cl}: 1.16-5.80, P=0.021)$. Additionally, male students were 8.44 times more likely to report sexual harassment than female participants $(\mathrm{AOR}=8.44,95 \% \mathrm{Cl}: 1.02-69.92, P=$ 0.048).

\section{Discussion}

This study examined how students' characteristics and aspects of the school environment are associated with experiences of being bullied among adolescents with ASD in the first year of middle school. To the best of our knowledge, this is the first study to examine the possible association between bullying victimization and classroom environments using a sample of seventh-graders with ASD. The results revealed that seventh-graders with ASD who had higher-quality friendships or who received assistance when encountering difficulties in school had a lower risk of being socially excluded at school. Regarding insults or teasing, the school environment was shown to play an essential role alongside the positive impact of adolescents' friendships. Students with ASD who experienced high social cohesion, harmony, and mutual assistance in regular classes had a lower risk of being insulted or teased by classmates. This finding indicates that social acceptance by fellow students could reduce the risk of students with ASD being victimized and suggests that a positive classroom environment is an essential factor that protects against both social exclusion and insults or teasing.

Hebron and Humphrey (2014) found that positive peer relationships are associated with lower bullying victimization levels. They argued that positive peer relationships could provide a friendly environment for learning social skills and are essential for protection against victimization [17]. The current findings are consistent with those from the studies of typically developing adolescents, which suggest that peer 
victimization is less likely to occur in a classroom environment comprised of positive, warm, and supportive peer relationships [27, 28]. Thus, efforts to reduce bullying should emphasize empathy among students in regular class settings.

Positive friendship quality, receiving social aid while at school, and a positive learning environment in the classroom all decrease the risk of being bullied. Typically developing students with higher-quality friendships are likely more likely to accept social support and connectedness and embrace diversity at school. These are the core elements of social capital [29]. Building social capital, a sense of community, and positive interpersonal and intergroup relationships at school are essential for preventing bullying [30]. Additionally, a friendly and supportive school environment that guides students with an unconditionally positive attitude also enhances social capital by promoting the belief that people are trustworthy, fair in their actions, and helpful when needed [31]. Regardless of whether anti-bullying efforts only focus on a single type of bullying, building social capital at schools is essential to developing social-ecological interventions to prevent the bullying of adolescents with ASD.

However, participants with more friends were more likely to be extorted or sexually harassed than those with fewer friends. This result contrasts with previous studies that found that students with ASD who had fewer friends at school were more likely to be victimized $[3,18]$. This suggests that having friends does not necessarily guarantee protection and support as some friends could be aggressive and abusive. Studies have indicated that a substantial proportion of bullying events occur within the boundaries of perceived friendships [32,33]. Additionally, regarding sexual harassment, a discrepancy often exists between the offenders' and victims' interpretations of behavioral intention. Rather than the aggressor's intent, the victim's perception may be more critical in identifying whether victimization has occurred. Finally, when individual characteristics were controlled for (i.e., sex, BMI, learning capability, and psychological distress), participants who were part-time in regular classes were more likely to be victims of sexual harassment than those who were full-time in regular classes. However, in general, the association between the amount of integration in regular classes and the sexual harassment of students with ASD is unclear and warrants further investigation.

Regarding the individual characteristics related to vulnerability, participants with more significant psychological distress were more likely to experience social exclusion and insults or teasing than those with lower levels of psychological distress. Previous studies have shown that depression, anxiety, and stress are significantly associated with bullying victimization among adolescents. The elevated levels of psychological distress resulting from these conditions constitute risk factors for bullying victimization [34-36]. In this study, male participants were more likely to have experienced sexual harassment than female participants. However, of the current sample of 184 students, only 17 were female. Therefore, there may not have been sufficient data to properly analyze the actual differences in experience between boys and girls. Future studies should compare the risk of sexual contact victimization among male and female adolescents with ASD and delineate the mechanisms that underlie any sex differences. 
In conclusion, the longitudinal/accumulated effects of bullying on adolescents with ASD seen during the first year of middle school represent pressing issues. However, the present study only examines the association between bullying victimization and social exclusion, insults or teasing, extortion, and sexual harassment in the school environment. This focus leaves the field open for future studies regarding the potential association between other types of bullying and the school environment and bullying studies outside schools / in special education classes [13].

\section{Limitations}

Instead of self-reporting bullying victimization, there is a significant essential need to use multiple informants, including parents and teachers $[37,38]$. In Taiwan, middle-school homeroom teachers do not typically remain in the classroom throughout the day, thus preventing said teachers from observing student interactions. Furthermore, adolescent students tend to be reluctant to tell their parents about their experiences in school. Again, as previously mentioned, the victim's perception, rather than the aggressor's intent, may be more crucial in identifying victimization. Therefore, the self-reported experiences of bullying victimization in this study are considered valid. However, bias or faulty awareness was likely present within these self-reports of interpersonal interactions. Future research on this population should further identify student-reporting bias and collect data from multiple informants.

\section{Conclusions}

Within this study cohort, approximately $85 \%$ of the seventh-graders with ASD had experienced at least one type of bullying. The data suggest that students with ASD are likely to become victims of bullying while adapting to new schools and during the period when peers form affiliations and adopt bullying behaviors to establish status. These results highlight the need for intervention and proactive prevention strategies against bullying to help students with ASD studying in regular classes during the first year of middle school. Moreover, the type of school environment strongly contributed to the risks of being victimized, depending on bullying. Unexpectedly, adolescents with ASD studying in a regular class setting had an elevated risk of bullying victimization. This finding underlines the complex mechanisms of bullying victimization in school environments.

Social support, positive friendships, and a positive learning environment were indicated among students as protective factors against bullying victimization. This finding can serve as reference data for the development of future anti-bullying programs designed for school settings. More programs that focus on inclusion and diversity are needed to aid adolescents with ASD who participate in regular class settings to prevent their likelihood of suffering from bullying. Positive school environments have been shown to help reduce the frequency of bullying behaviors $[39,40]$. Implementing more steps toward this goal is expected to facilitate the successful integration of students with ASD into regular class settings.

\section{Abbreviations}


ASD

autism spectrum disorder

SCL-6

Symptom Checklist-90-Revised

SNELS

Special Needs Education Longitudinal Study

\section{Declarations}

Authors' contributions: $\mathrm{HH}$ applied the database; $\mathrm{HH}$ and DR designed the analysis and analysed the results; $\mathrm{HH}, \mathrm{DR}$ and $\mathrm{AK}$ wrote the manuscript and contributed to editing the manuscript. All authors read and approved the fnal manuscript.

Ethics approval and consent to participate: The informed consentwas provided by all respondent.

Availability of data and materials: The data that support the findings of this study are available in the Special Needs Education Longitudinal Study (SNELS) database, released from the Survey Research Data Archive of Academia Sinica but restrictions apply to the availability of these data, which were used under license for the current study, and so are not publicly available. Data are however available from the authors upon reasonable request and with permission of the Survey Research Data Archive of Academia Sinica.

Conflict of Interest Disclosures (includes financial disclosures): The authors have no conflicts of interest to disclose.

Funding/Support: The submission of this paper (article) was funded by a grant to $\mathrm{H}-\mathrm{H}$ Lu from the Ministry of Science and Technology, Taiwan (MOST107-2410-H-040 -002 - and MOST108-2410-H-040010-MY3).

Role of Funder/Sponsor (if any): The Ministry of Science and Technology had no role in the design and conducting of the study.

Acknowledgements: Data analyzed in this article were collected by the research project "the Special Needs Education Longitudinal Study" sponsored by the Academia Sinica. This research project was carried out by Department of Special Education, National Taiwan Normal University, and directed by Dr. Tien-miau Wang. The Center for Survey Research of Academia Sinica is responsible for the data distribution. The authors appreciate the assistance in providing data by the institutes aforementioned. The views expressed herein are the authors' own

\section{Consent for publication: Not applicable}

\section{References}


1. Rose CA, Monda-Amaya LE, Espelage DL. Bullying perpetration and victimization in special education: A review of the literature. Remedial Spec Educ. Sage Publications Sage CA: Los Angeles, CA; 2011;32:114-30.

2. Weiss JA, Fardella MA. Victimization and perpetration experiences of adults with autism. Front Psychiatry. Frontiers; 2018;9.

3. Cappadocia MC, Weiss JA, Pepler D. Bullying experiences among children and youth with autism spectrum disorders. J Autism Dev Disord. Springer; 2012;42:266-77.

4. Forrest DL, Kroeger RA, Stroope S. Autism Spectrum Disorder Symptoms and Bullying Victimization Among Children with Autism in the United States. J Autism Dev Disord. 2020;50:560-71.

5. Hoover DW. The effects of psychological trauma on children with autism spectrum disorders: a research review. Rev J Autism Dev Disord. Springer; 2015;2:287-99.

6. Liu M-J, Ma L-Y, Chou W-J, Chen Y-M, Liu T-L, Hsiao RC, et al. Effects of theory of mind performance training on reducing bullying involvement in children and adolescents with high-functioning autism spectrum disorder. PLoS One. Public Library of Science San Francisco, CA USA; 2018;13:e0191271.

7. Van Roekel E, Scholte RH, Didden R. Bullying among adolescents with autism spectrum disorders: Prevalence and perception. J Autism Dev Disord. Springer; 2010;40:63-73.

8. Weiss JA, Cappadocia MC, Tint A, Pepler D. Bullying victimization, parenting stress, and anxiety among adolescents and young adults with autism spectrum disorder. Autism Res. Wiley Online Library; 2015;8:727-37.

9. Hebron J, Humphrey N. Exposure to bullying among students with autism spectrum conditions: A multi-informant analysis of risk and protective factors. Autism. SAGE Publications Ltd; 2014;18:61830.

10. Maïano C, Normand CL, Salvas M-C, Moullec G, Aimé A. Prevalence of School Bullying Among Youth with Autism Spectrum Disorders: A Systematic Review and Meta-Analysis. Autism Res. 2016;9:60115.

11. Holden R, Mueller J, McGowan J, Sanyal J, Kikoler M, Simonoff E, et al. Investigating bullying as a predictor of suicidality in a clinical sample of adolescents with autism spectrum disorder. Autism Res. 2020;13:988-97.

12. Rodriguez G, Drastal K, Hartley SL. Cross-lagged model of bullying victimization and mental health problems in children with autism in middle to older childhood. Autism. 2021;25:90-101.

13. Swearer SM, Hymel S. Understanding the psychology of bullying: Moving toward a social-ecological diathesis-stress model. Am Psychol. 2015;70:344-53.

14. Zych I, Farrington DP, Ttofi MM. Protective factors against bullying and cyberbullying: A systematic review of meta-analyses. Aggress Violent Behav. Elsevier; 2019;45:4-19.

15. Costantino C, Casuccio A, Marotta C, Bono SE, Ventura G, Mazzucco W, et al. Effects of an intervention to prevent the bullying in first-grade secondary schools of Palermo, Italy: the BIAS study. Ital J Pediatr. BioMed Central; 2019;45:1-9. 
16. Fraguas D, Díaz-Caneja CM, Ayora M, Durán-Cutilla M, Abregú-Crespo R, Ezquiaga-Bravo I, et al. Assessment of school anti-bullying interventions: a meta-analysis of randomized clinical trials. JAMA Pediatr. American Medical Association; 2021;175:44-55.

17. Sreckovic MA, Brunsting NC, Able H. Victimization of students with autism spectrum disorder: A review of prevalence and risk factors. Res Autism Spectr Disord. Elsevier; 2014;8:1155-72.

18. Zablotsky B, Bradshaw CP, Anderson CM, Law P. Risk factors for bullying among children with autism spectrum disorders. Autism. Sage Publications Sage UK: London, England; 2014;18:419-27.

19. Troop-Gordon W. Peer victimization in adolescence: The nature, progression, and consequences of being bullied within a developmental context. J Adolesc. Elsevier; 2017;55:116-28.

20. Mandy W, Murin M, Baykaner O, Staunton S, Hellriegel J, Anderson S, et al. The transition from primary to secondary school in mainstream education for children with autism spectrum disorder. Autism. SAGE Publications Sage UK: London, England; 2016;20:5-13.

21. Chan HCO, Wong DS. The overlap between school bullying perpetration and victimization: Assessing the psychological, familial, and school factors of Chinese adolescents in Hong Kong. J Child Fam Stud. Springer; 2015;24:3224-34.

22. Matthias C, LaVelle JM, Johnson DR, Wu Y-C, Thurlow ML. Exploring predictors of bullying and victimization of students with autism spectrum disorder (ASD): findings from NLTS 2012. J Autism Dev Disord. Springer; 2021;1-12.

23. Park I, Gong J, Lyons GL, Hirota T, Takahashi M, Kim B, et al. Prevalence of and factors associated with school bullying in students with autism spectrum disorder: A cross-cultural meta-analysis. Yonsei Med J. Yonsei University College of Medicine; 2020;61:909.

24. Huang YR. Using hierarchical linear model to analyze the factors influencing living skills of senior high school students with disabilities. J Spec Educ. 2013;37:93-112.

25. Derogatis LR, Melisaratos N. The brief symptom inventory: an introductory report. Psychol Med. Cambridge University Press; 1983;13:595-605.

26. Wang W, Wu C. Scaling issues in longitudinal studies: The Symptom checklist-90-Revised as an empirical example. Formosa J Ment Health. 2003;16:1-30.

27. Thornberg R, Wänström L, Hong JS, Espelage DL. Classroom relationship qualities and socialcognitive correlates of defending and passive bystanding in school bullying in Sweden: A multilevel analysis. J Sch Psychol. Elsevier; 2017;63:49-62.

28. Thornberg R, Wänström L, Jungert T. Authoritative classroom climate and its relations to bullying victimization and bystander behaviors. Sch Psychol Int. Sage Publications Sage UK: London, England; 2018;39:663-80.

29. Carney JV, Liu Y, Hazler RJ. A path analysis on school bullying and critical school environment variables: A social capital perspective. Child Youth Serv Rev. Elsevier; 2018;93:231-9.

30. Mortensen J, Lichty L, Foster-Fishman P, Harfst S, Hockin S, Warsinske K, et al. Leadership through a youth lens: Understanding youth conceptualizations of leadership. J Community Psychol. Wiley Online Library; 2014;42:447-62. 
31. Carney JV, Jacob CJ, Hazler RJ. Exposure to school bullying and the social capital of sixth-grade students. J Humanist Couns. Wiley Online Library; 2011;50:238-53.

32. Mishna F, Wiener J, Pepler D. Some of my best friends--experiences of bullying within friendships. Sch Psychol Int. Sage Publications Sage UK: London, England; 2008;29:549-73.

33. Wei H-S, Jonson-Reid M. Friends can hurt you: Examining the coexistence of friendship and bullying among early adolescents. Sch Psychol Int. Sage Publications Sage UK: London, England; 2011;32:244-62.

34. Arhin DK, Asante KO, Kugbey N, Oti-Boadi M. The relationship between psychological distress and bullying victimisation among school-going adolescents in Ghana: a cross-sectional study. BMC Res Notes. BioMed Central; 2019;12:1-5.

35. Hansen TB, Steenberg LM, Palic S, Elklit A. A review of psychological factors related to bullying victimization in schools. Aggress Violent Behav. Elsevier; 2012;17:383-7.

36. Tipton-Fisler LA, Rodriguez G, Zeedyk SM, Blacher J. Stability of bullying and internalizing problems among adolescents with ASD, ID, or typical development. Res Dev Disabil. Elsevier; 2018;80:131-41.

37. Shakoor S, Jaffee SR, Andreou P, Bowes L, Ambler AP, Caspi A, et al. Mothers and children as informants of bullying victimization: results from an epidemiological cohort of children. J Abnorm Child Psychol. Springer; 2011;39:379-87.

38. Totura CMW, Green AE, Karver MS, Gesten EL. Multiple informants in the assessment of psychological, behavioral, and academic correlates of bullying and victimization in middle school. $J$ Adolesc. Elsevier; 2009;32:193-211.

39. Konishi C, Miyazaki Y, Hymel S, Waterhouse T. Investigating associations between school climate and bullying in secondary schools: Multilevel contextual effects modeling. Sch Psychol Int. Sage Publications Sage UK: London, England; 2017;38:240-63.

40. White N, La Salle T, Ashby JS, Meyers J. A brief measure of adolescent perceptions of school climate. Sch Psychol Q. Educational Publishing Foundation; 2014;29:349-59.

\section{Figures}


317 seventh-graders with ASD from the

SNELS study in 2011

Excluded:

94 were in special

education classrooms

and schools on a full-

time basis.

223 were in regular

classes in general

education schools on a

full-time or part-time

basis.

Excluded:

39 were missing data

for measurement

184 were enrolled in the analysis

\section{Figure 1}

Flow chart of the selection process of study participants. 